\title{
A VARIANT OF THE SINCIPITAL T IN PERU
}

\author{
ROY L. MOODIE
}

Department of Anatomy, University of Illinois, Chicago.

A study of primitive and prehistory surgery ${ }^{1}$ is a phase of anthropology which furnishes considerable information to our knowledge of Paleopathology The operations were usually performed to relieve some defect, either traumatic or otherwise, and the surgical results themselves were very often in the nature of severe lesions, the study of which falls within the scope of our subject.

Among several other interesting objects illustrating various phases of Paleopathology, loaned the writer through Dr. L. R. Sullivan by the American Museum of Natural History, is a female skull from Amazonas, Peru, (B. 6684), presumably pre-Columbian, which shows on its vertex the pathology suggested by the title of this paper. It indicates the use of the cautery among the ancient Peruvians, a practice which so far as I can determine, has not hitherto been recorded among the races which inhabited Peru in early times.

We owe to the excellent deductions of Manouvrier, ${ }^{2}$ which have been discussed by Sudhoff, ${ }^{3}$ and MacCurdy, ${ }^{4}$ our first clear interpre-

1The writer has contributed several essays on various phases of this subject to the Surgical Clinics of Chicago. Attention is called to them here since the serial may not be known to anthropologists, and there is some new material in the papers. The subjects and dates are:

(1). Studies in Paleopathology: Ancient Skull Lesions and the Practice of Trephining in Prehistoric Times. June, 1919, 481-496, figs. 139-149.

(2). Studies in Paleopathology: The Diseases of the Ancient Peruvians, and some Account of Their Surgical Practices. February, 1920, 211-231, figs. 72-83

(3). Primitive Surgery in Ancient Egypt. April, 1920.

(4). The Antiquity of Pott's Disease and other Spinal Lesions; Primitive Treatment. June, 1920.

(5). The Use of the Cautery among Neolithic and Later Primitive Peoples. August, 1920.

2L. Manouvrier. 1903. Les marques sincipitales des crânes néolithiques considerées comme reliant la chirurgie classique ancienne á la chirurgie préhistorique. Bull. et Mém. Soc. Anthrop. Paris, 5e sér, iv., 494.

3SudhoFF (KARL), 1909 Medizin in der Steinzeit. Z. f. ärtzl. Fortbildung. 6 Jahrg, No. 6, 196-200.

${ }^{4}$ MacCURdy (G. G.), 1905. Prehistoric Surgery, a Neolithic Survival. Amer. Anthropol., vii, 17-23, pl. 1. Contains a digest of Manouvrier's results with references. Same figure in the two papers.

Amer. Jour. Phys. Anthrop., Vol. IV, No. II 
tation of the curious T-shaped lesions seen on skulls, usually female, of many different periods from the Neolithic down. According to Sudhoff ${ }^{1}$ skulls with lesions indicating this procedure are known from northern France (near Mantes, the type locality), Central Asia, Canary Islands, Africa, and I believe we are now able to add Peru. The procedure was used to relieve, as a therapeutic measure, epilepsy or other nervous maladies accompanied by convulsions, and Manouvrier concluded that the operation, which was initiated in Neolithic times, was handed down without change to the surgeons of the Middle Ages. The efficacy of the practice is assured since the most stubborn fit of melancholia would doubtless react violently to the application of boiling oil to a cruciate incision made in the scalp with a rough flint knife. The patient would assuredly take a lively interest in affairs for a time at any rate. It is doubtful if modern surgery has offered a cure for melancholia which is as effective, and certainly none so painful.

The crude incision, the dirty oil and the unwashed skin doubtless always resulted in a severe scalp infection which acted more or less directly upon the subjacent skull and produced lesions of more or less severity. Pathological changes in bone go on very rapidly and we are apprised of this rapidity by Keith's study of bone injuries ${ }^{2}$ in the recent war, where it is shown that extensive bone changes and relatively huge osteophytes develop in as short a period as seven weeks. Keith's study enables us to judge, more or less closely, the duration of an infection in an ancient skull from the severity of the lesion.

We are thus within the bounds of experience when we say that the lesions in the ancient Peruvian female skull, though extensive, were not due to an infection of long duration, and possibly the scalp healed after a very few weeks. The lesions take the shape of a cross on the vertex of the skull involving the sagittal and lambdoid sutures. The saggital incision from the coronal suture back nearly to the foramen magnum has a length of $190 \mathrm{~mm}$. The borders of the transverse lesion are within the limits of the vertex and have a length of $140 \mathrm{~mm}$. The outer table is thickened to $3 \mathrm{~mm}$. The diploe is slightly increased (to $5 \mathrm{~mm}$.) while the inner table is not affected. The vertex is roughened and there are many small separate knob-like growths.

1StDhofF (Karl), 1908. Le T-sincipital Néolithique etc. Bull. Soc. franc. d'hist. de la Méd., Paris, vii., 175-179.

2Keith (ARThtr), 1920. Specimens of Long Bones showing the Processes: of Infection and Repair. Brit. J. Surg., vii., 302-319, figs. 272-300. 
The entire area covered by rugosities has an extent of over 140 sq. $\mathrm{cm}$. The most prominent lesions are the ridges, in the shape of a Latin cross (crux immissa), with the longer portion of the upright extending anteriorly on the frontals and parietals, thus forming a variant of the sincipital $T$, practiced in Neolithic times in France. It would seem, from the pathology, that the scalp had pulled apart at the lines of incisions and in this space had developed a thickening of the outer table, and the adjacent areas had become carious through the agency of the infection which must have been for a time, a violent one.

Microscopic examination of a section of the right parietal ridge shows a tendency for the osseous lamellae to arrange themselves in the form of pseudo-Haversian systems, usually incomplete, being cut off by an invading vascular channel. The lacunae are all provided with an abundance of canaliculi which anastomose in the deeper layers. As one approaches the surface layers anastomosis disappears, the lacunae become irregular in shape, often rounded, and the canaliculi are irregular and distorted.

The lesions are evidently due to a scalp infection, and the form which the lesions take have suggested to me the possibility of offering the above explanation. It is no new thing to find expressions of primitive ideas in widely separated regions since the practice of trephining was common in France and in Peru. The idea will, of course require confirmation from other observations since a deduction founded on a single occurrence is not conclusive. The interpretation is, however, offered as an explanation of the pathology of the pre-Columbian female skull from Peru.

Plate I. Skull of a female Peruvian Indian of supposedly Pre-Columbian age, from Amazonas, Peru. The vertex shows the large cruciate ridge, shown diagramatically in the small upper left-hand figure, due possibly to a scalp incision for the purpose of using the cauterizing substance or it may have been done by the actual cautery. At any rate the lesions on the skull are evidently. the result of a severe scalp infection which may have been due to the cautery. The regular cross-shaped lesion cannot be interpreted as accidental injury but bears all the evidences of design, and it may be regarded as related to the Sincipital-T described by Manouvrier from the Neolithic tumuli of France. Other evidence will be needed to substantiate this interpretation.

The small figure in the lower right-hand corner shows a section, enlarged four diameters, taken through the ridge on the right parietal showing the hypertrophy of the outer table, which is very compact and filled with partially developed Haversian systems, the diploe slightly enlarged and the inner table little changed. 
Plate II, Figure 1. Lateral view of the female skull from Peru. The results of cauterization may be seen in the undulating surface of the occiput, the roughened aspect of the right parietal and in the sagittal ridge.

FIGURE 2. Occipital view giving some idea of the great extent posteriorly of the lesions, well shown in Plate I. The height of the anterior sagittal ridge is clearly shown. This is continued across the inion as a posterior ridge. The skull had lain for years partially embedded in soil, but there is no apparent surface change in the bone due to weathering. Immediately to the right of the inion a small section was taken out for microscopic examination. The opening, being filled with plaster appears more smooth than its adjoining territory. It is also somewhat darker. The drawing, Plate I, was made before the material for sectioning was removed. Careful microscopic examination of the sections made. shows no effects due to weathering. The photographs are untouched. 


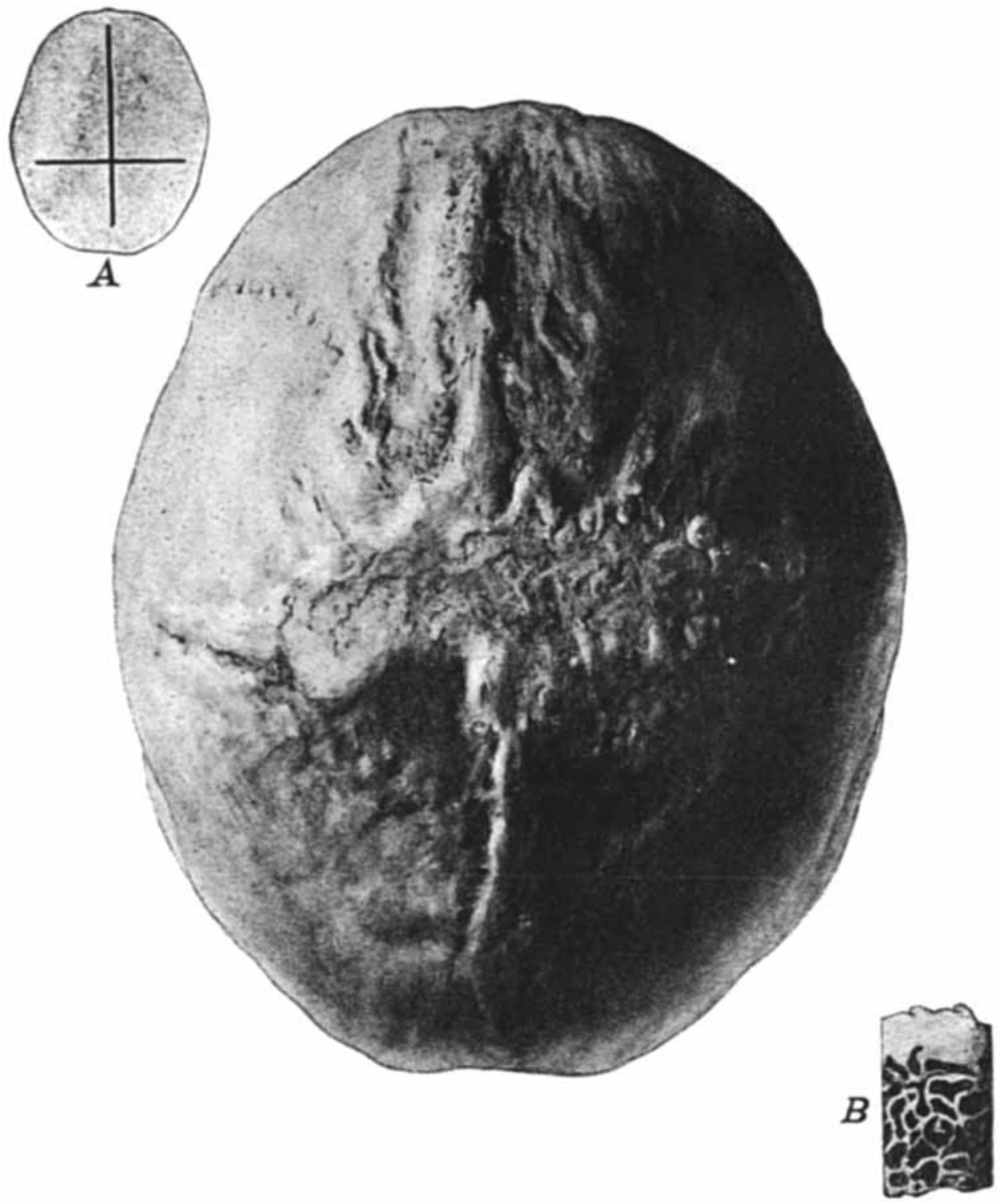

Plate I. 


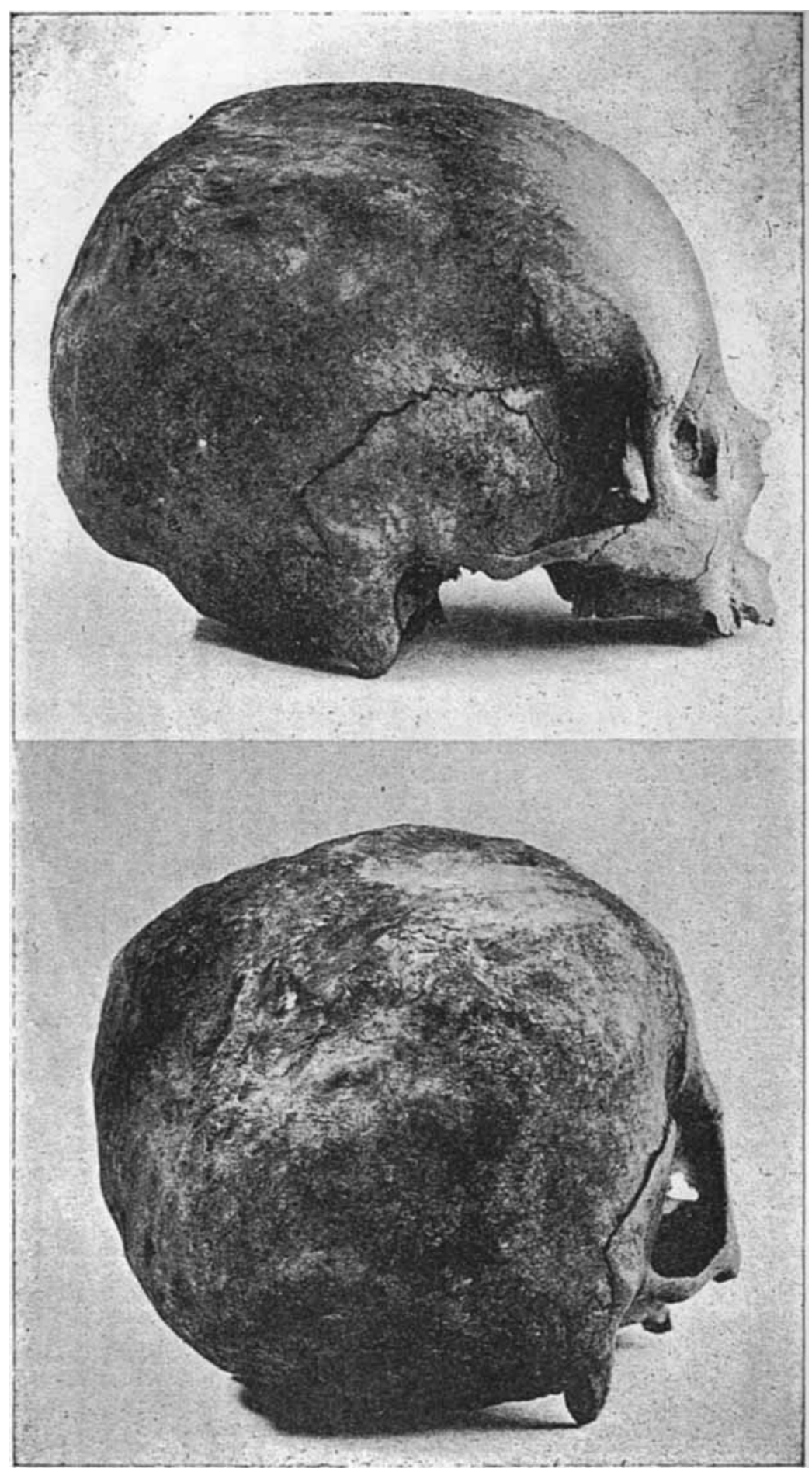

Plate II 